\title{
Student Perspectives on Wireless Communication Technologies to Facilitate Inclusion in Field Activities
}

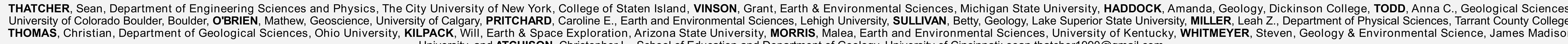

Abstract

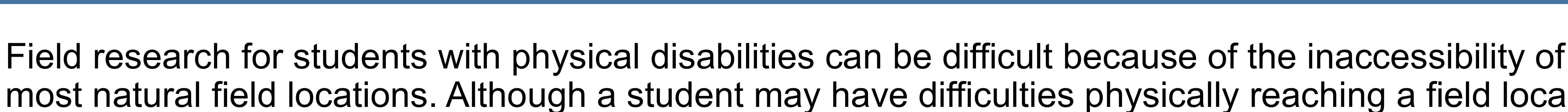
tion, he or she can still be involved in research initititives by accessing the field site remotely by uctiliz-

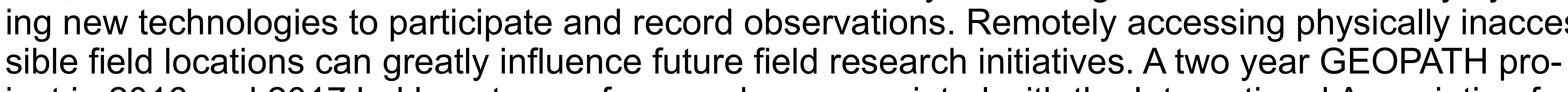
Iect in 2016 and 2017 led by a team of researchers associated with the International Association tor
Gooscieince Diversity and funded by the National Scieince F Fundation, brought together a cohort of

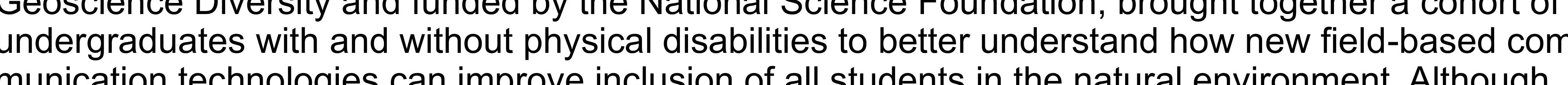
here was IImited success with ypicical conmuniccation devices such as walkie-takikes, the most suc-

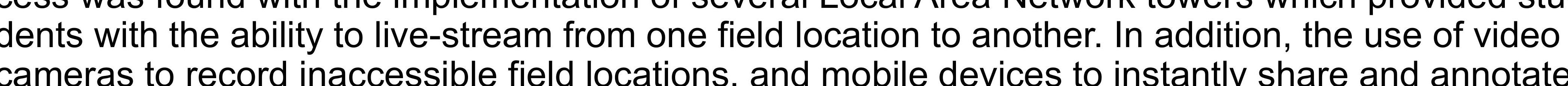

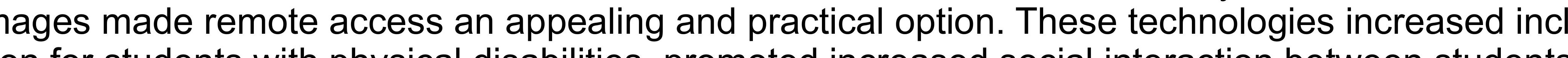
sion for students with physical cisabilites, promoted increased social therection
and emphasized the importance of collaboration, both within and between groups

Introduction

Field research is an important component for all geoscience programs, but for students with physical
limititations it can be difficult due to the natural inaccessibility of many field locations. A two year GEO-

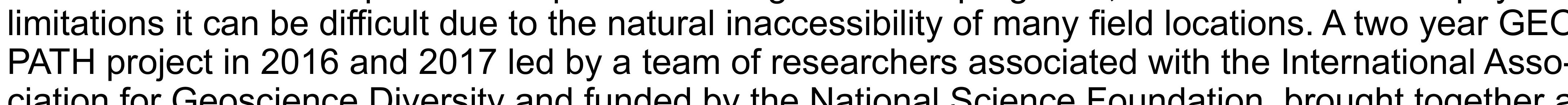
cohort of undergraduates with and without physical disabilitites sto better en nuderstand how new field政 Ireland in 2017 to trial typical field based communication technologies and more modern communuication to understand the beneffits and limitations for inclusive field research endeavors. Some of the lo-
cations visited in Arizona included the Grand Canyon, SP Crater, and Meteor Crater, while in Western Ireliand field locations included Killke, Renville Point, and Connemarara Recess
and

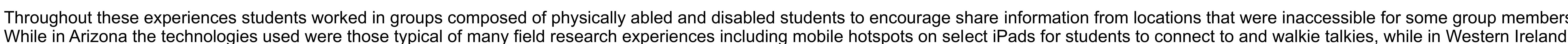
LAN - local area networks - were used to allow students to i instantly livestream videos from inaccessibile locations at the field sites share phototographs with ohther group members.
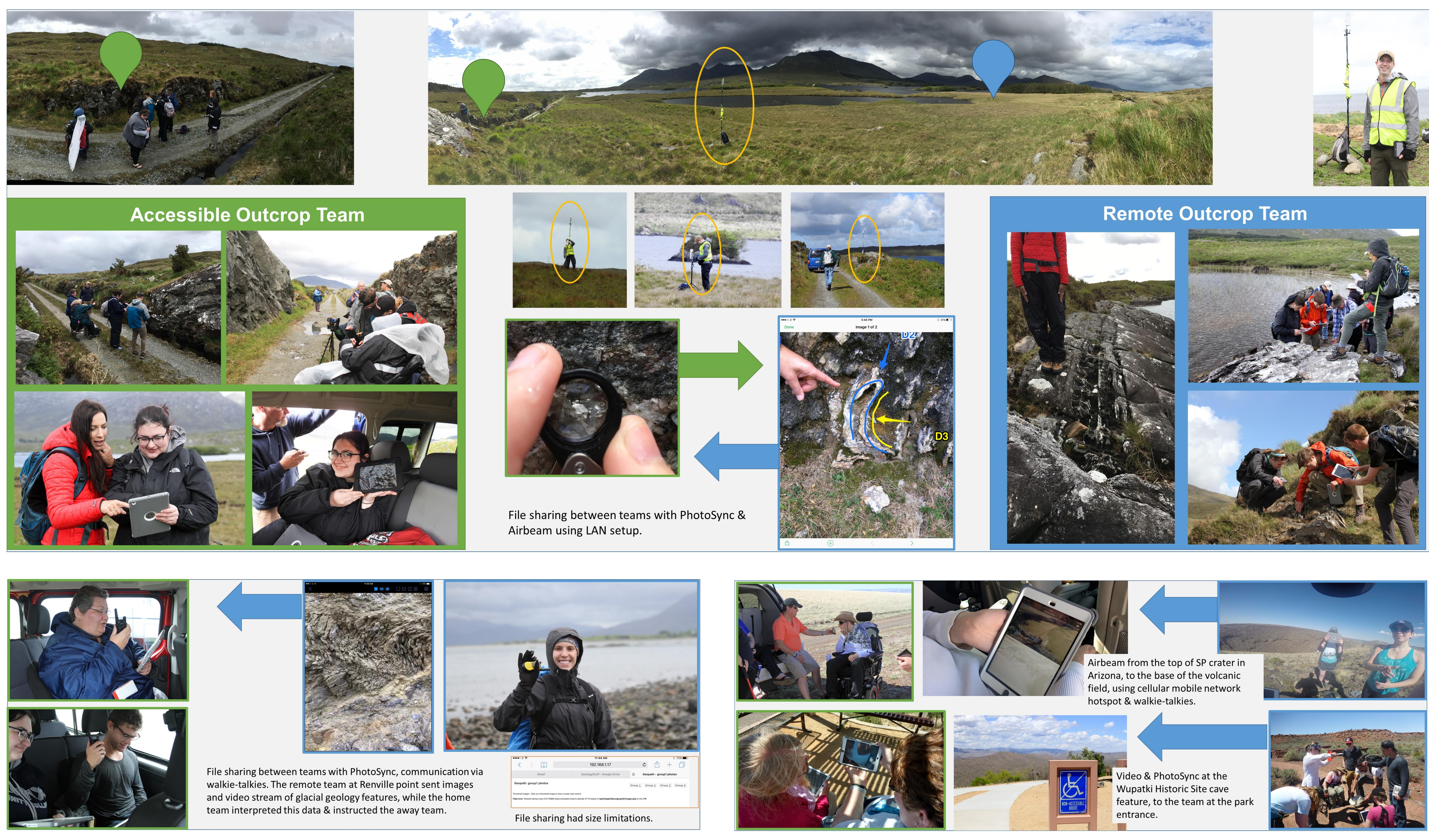

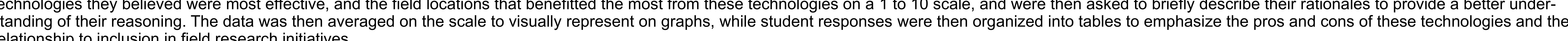

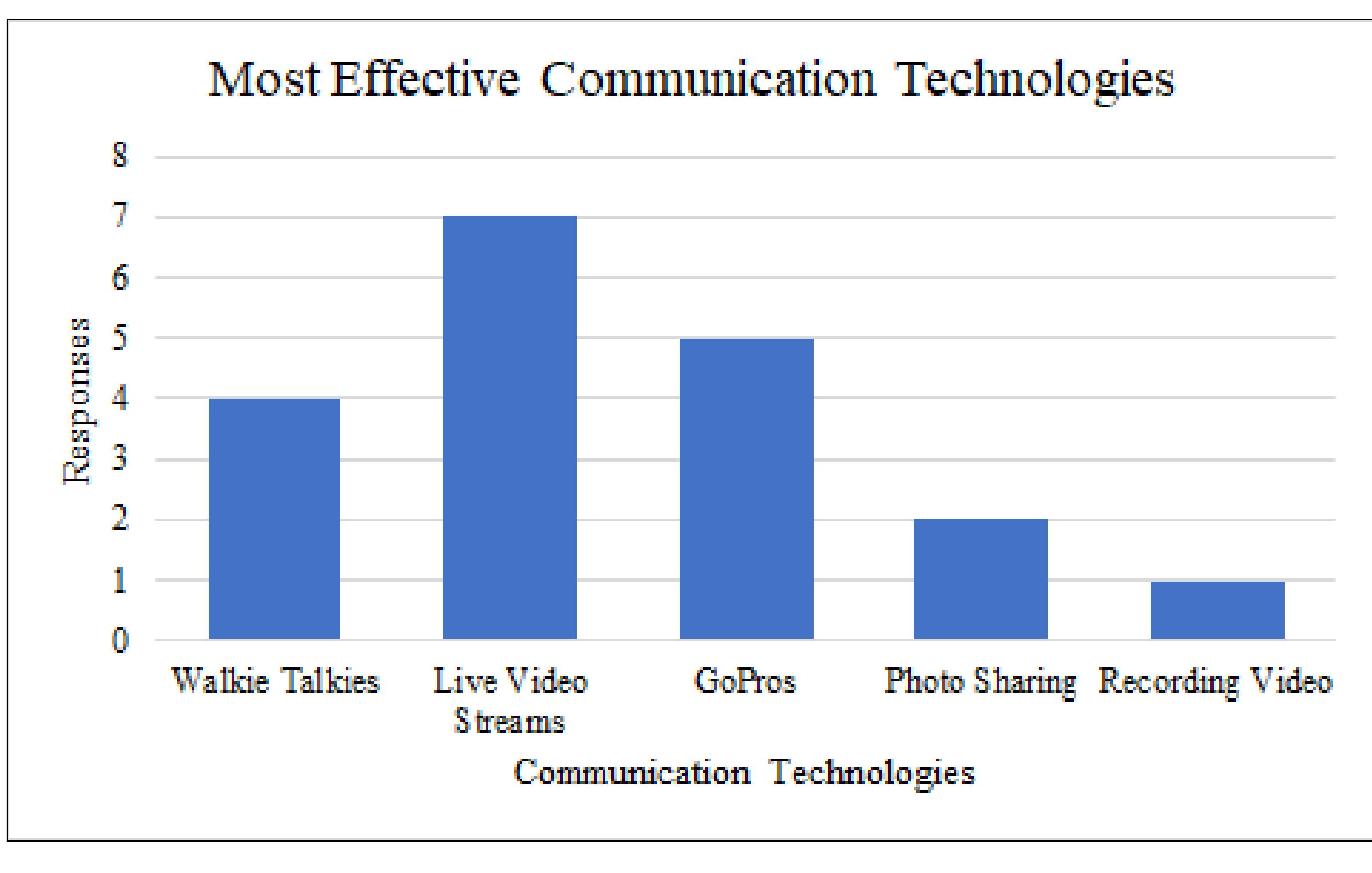

Figure 1: The most teffective communication technologies used in the field during the
two year period of the GEPATH project. Live video streams and GoPro recordings

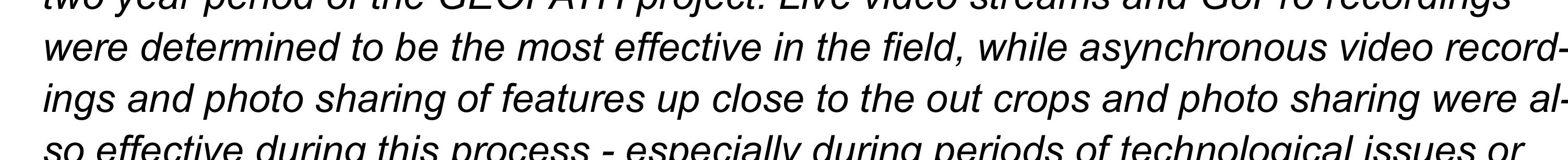

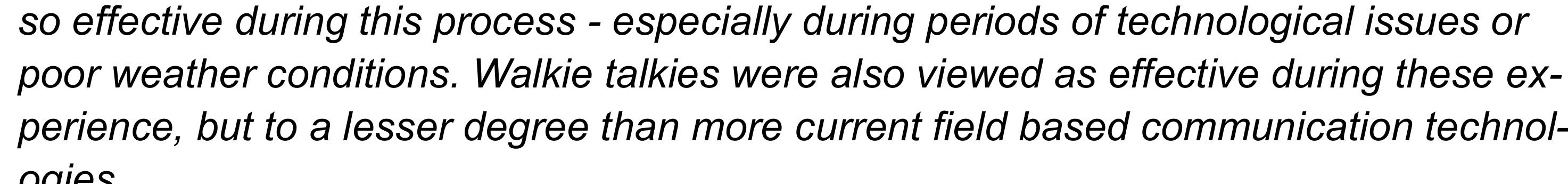

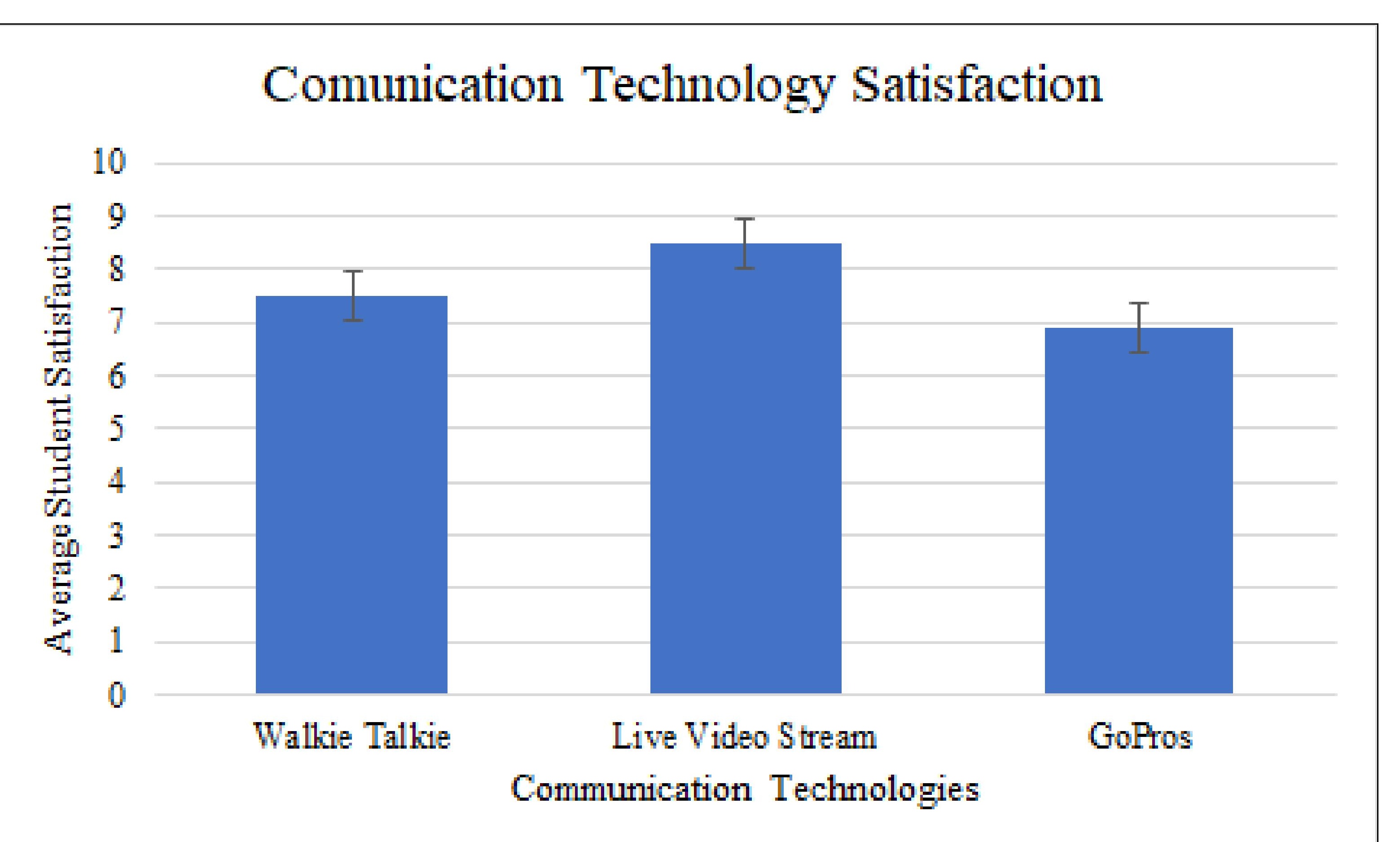

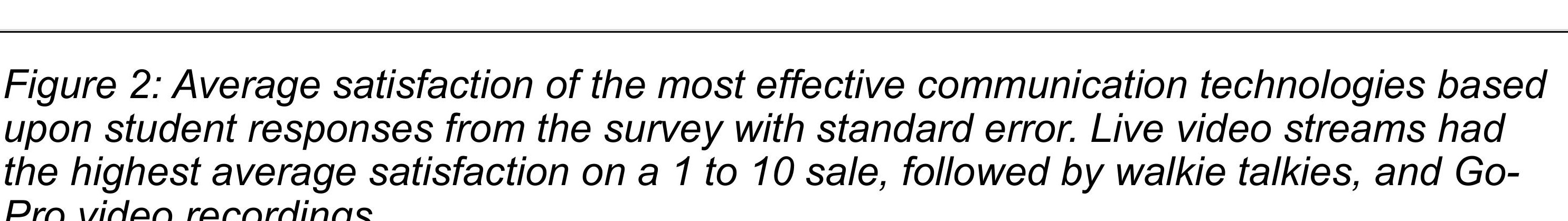

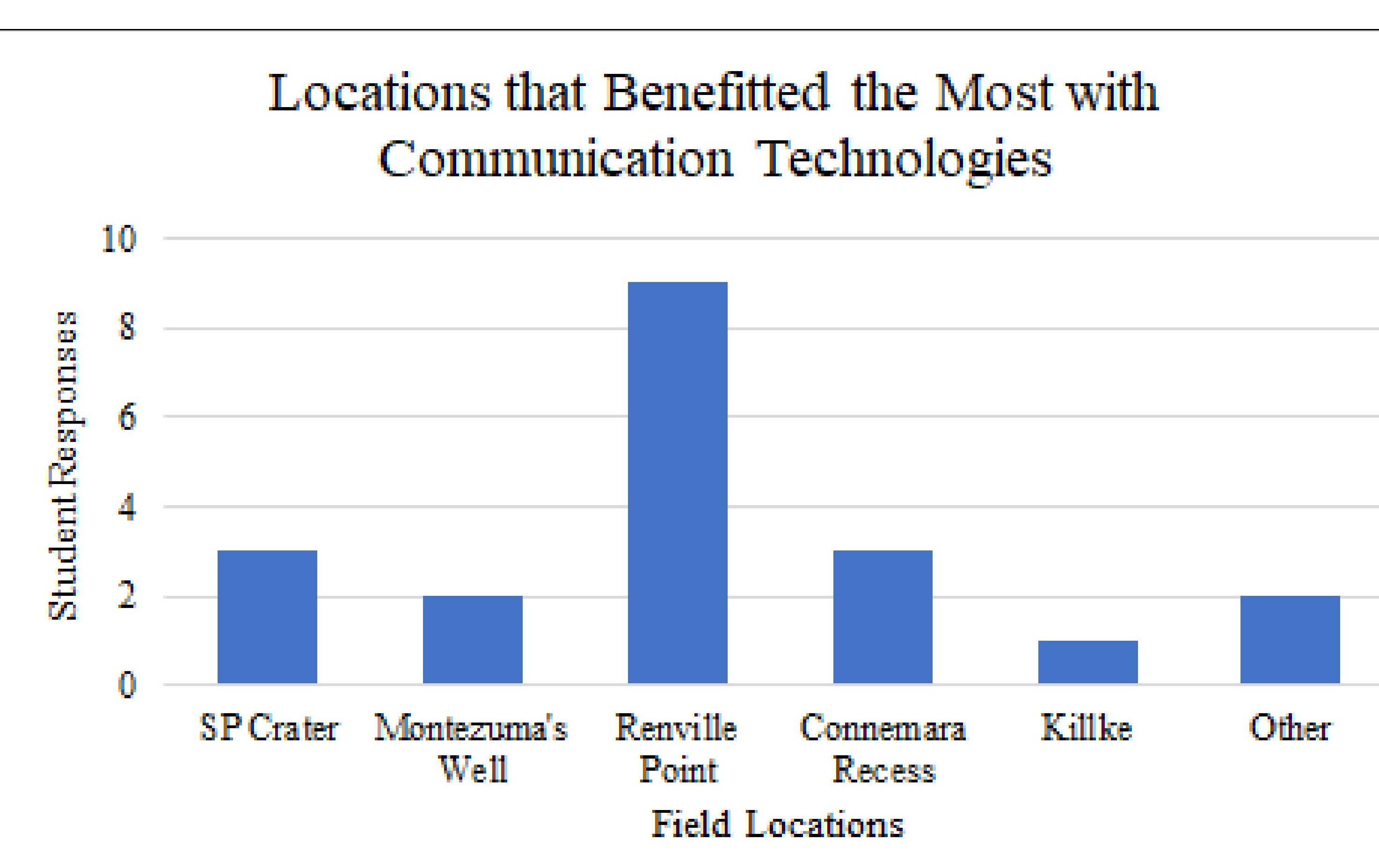

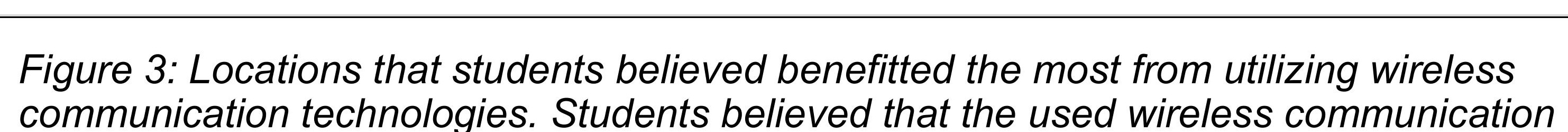

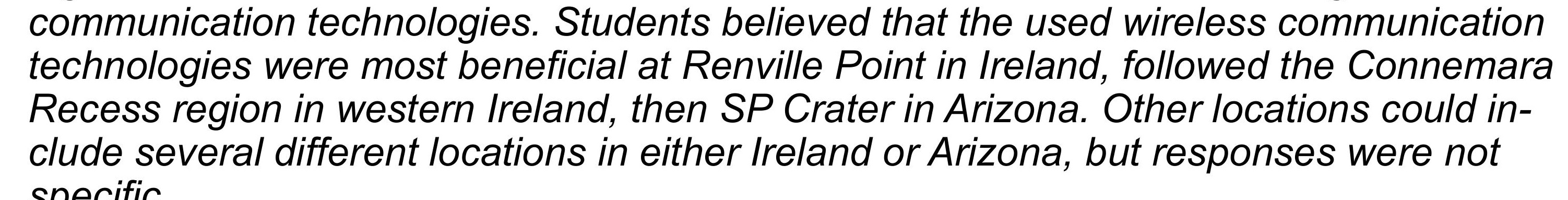

Technological Pros and Cons

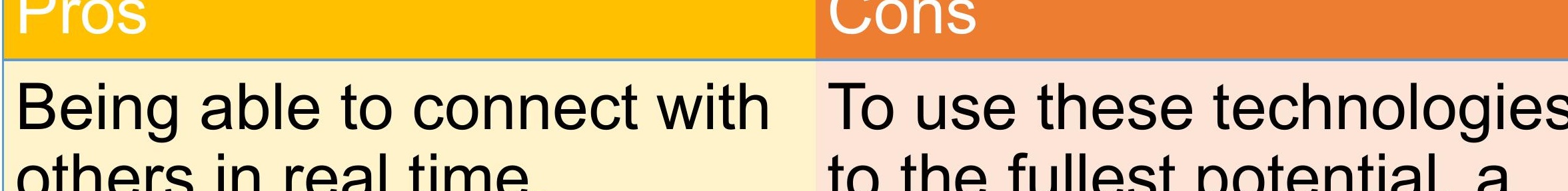
$\begin{array}{ll}\text { others in real time. } & \begin{array}{l}\text { to the fullest potential, a } \\ \text { strong Wifi signal is re- } \\ \text { quired. }\end{array}\end{array}$

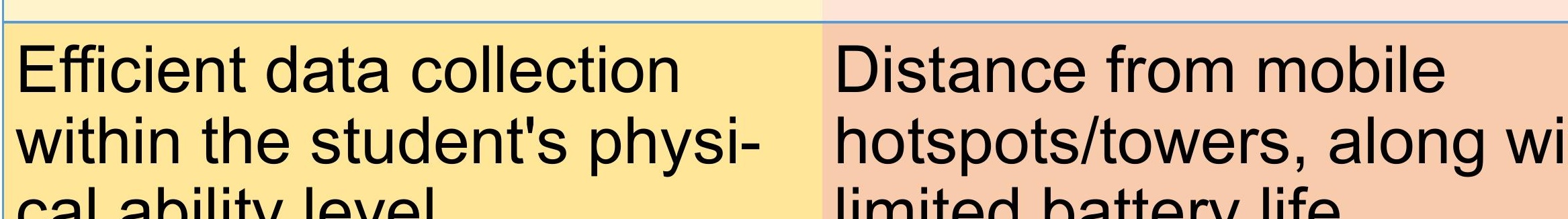
cal ability level. Eliminates physical barriers Steep learning curve if in-
for physically disabled stu- experienced with new
$\begin{aligned} & \text { dents. } \\ & \text { technologies. }\end{aligned}$ Encourages students to Time to troubleshoot inevitable bugs - not connecting
learning, rather than taking to devices, lag times, and a backseat in educational other technological issues.
activities.

Table 1: A summary of student responses discussing the pros and

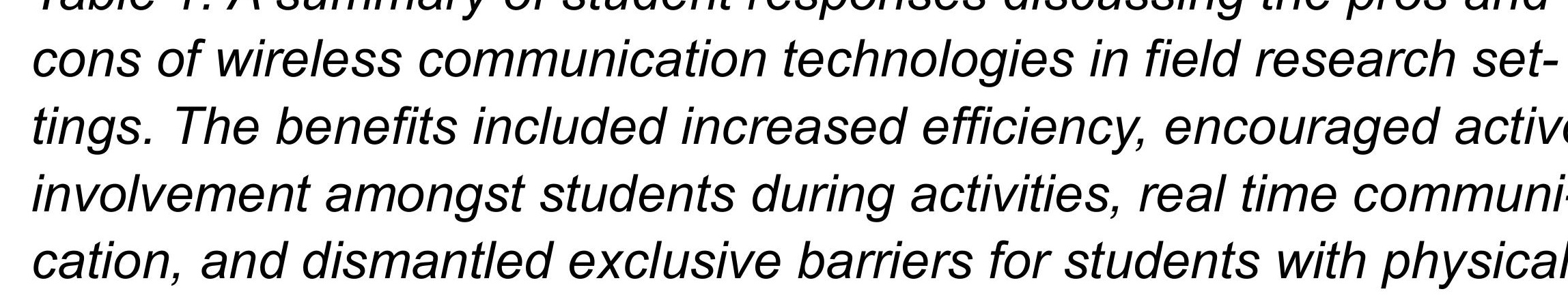

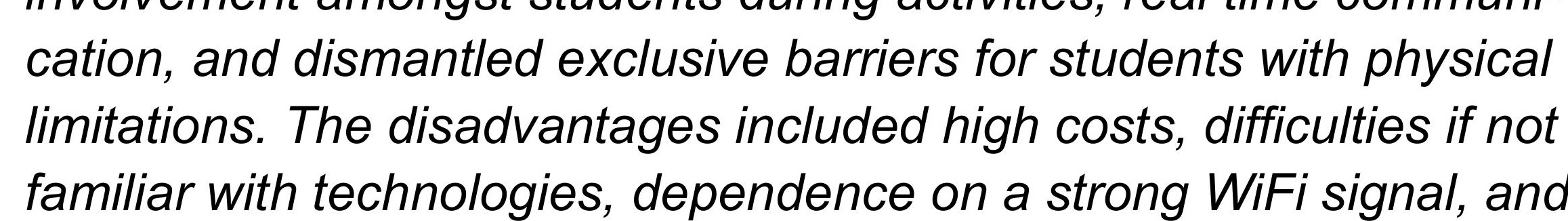

Pros and Cons for Inclusion Emotional satisfaction know- Training on how to use ing that you were able to these technologies is i inyou would not physically be gagement.
able to independently.

Encouraged conversations Highly expensive for indiamongst students with differ- vidual students or dep in funds to buy without Provided students with the Lag between technolo-
ability to engage in conver- gies could make inclu-
sations by recording them group

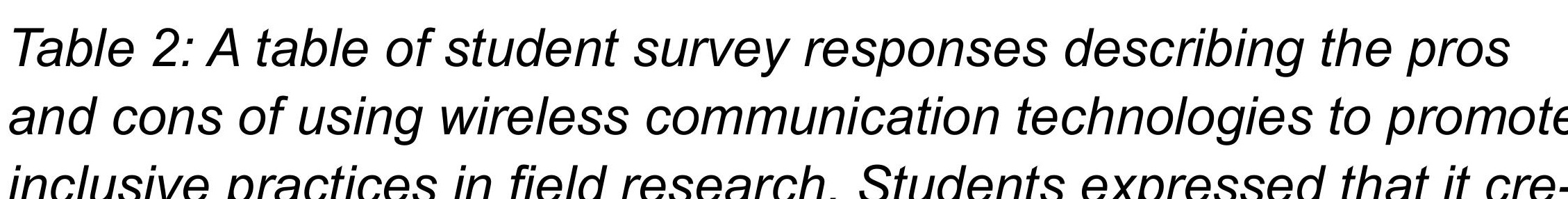

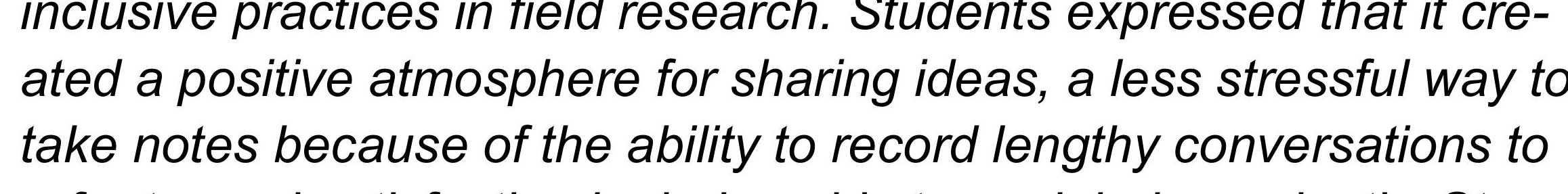
dents also expressed the need for training on how to use the the tech-

Discussion

On a 1 to 10 scale, students experienced an average satisfaction of 8.9 for the two years of the project in regards

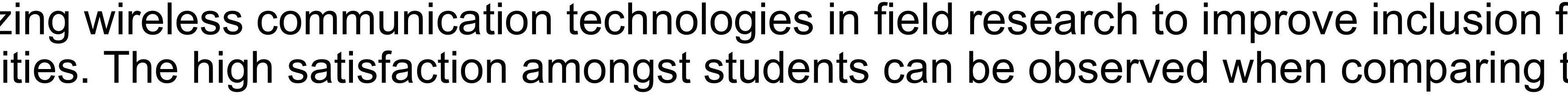
The students determined that these technologies were beneficiai in in educcational ennivionment because it allowed them to engage in conversations about field locations despite the locations accessibility, created an active earning
environment the promoted student participation, and crowdsourced data collection allowed large areas - specifical-
ly kilke - to be analyzed in a short amount of time - Table 1 . It is also worth noting that live video streams were more preferable than the more commonly used walkie takkies in field research because it allowed students that
could not physically access the locations to observe outcrop features in real time alongside their peers, rather than hearing about them. From an inclusion perspective these technologies assisted in bridging educational gaps be-
ween lower level undergraduates - freshman and sophomores - and upper level undergraduates - juniors and senors - and educational backgrounds, provided emotional gratification for students with physical limitations that
would not be able to participate in field activities like this without these technologies, prymoted interesting conversations about field locations in real time, and eliminated some stress because conversations could be recorded
and referred back to when making notes - Table 2. Despite the overwhelmingly positive experience, cons that were main in close proximity to mobile Wifi towers, and inexperience with some of the technologies - Table 1 . It is also

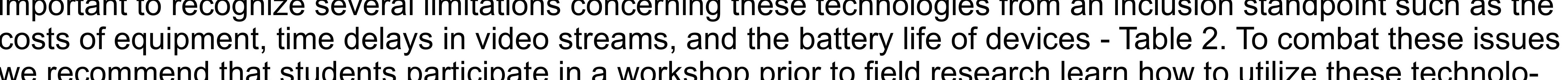
we recommend that students participate in a workshop prior to field research learn how to utilize these technolonovel ways.
novelo 